\title{
Epidemiology of Pertussis in Pregnant Women of Tehran, Iran
}

\author{
Shima Javadinia ${ }^{1}$, Ali Badamchi ${ }^{2}$, Zahra Movahedi ${ }^{3}$, Mehdi shekarabi ${ }^{3}$, Leila Tahernia ${ }^{3}$, Mahbod Jafarvand ${ }^{3}$ and \\ Azardokht Tabatabaei ${ }^{3 *}$
}

${ }^{1}$ Department of Lung disease, Zabol University of Medical Sciences, Iran

${ }^{2}$ Department of Microbiology, Zabol University of Medical Sciences, Iran

${ }^{3}$ Research Center of Pediatric Infectious Disease, Qom University of Medical Sciences and Health services, Iran

Submission: April 24, 2018 ; Published: November 30, 2018

*Corresponding author: Azardokht Tabatabaei, Research Center of Pediatric Infectious Disease, Qom University of Medical Sciences and Health services, Tehran, Iran

*Hazrat-e-Rasuol Akram Hospital, Niayesh St, Sattarkhan Ave, Iran University of Medical Sciences and Health Services, Tehran, Iran

Abstract

Backgrounds: Pertussis is a contagious respiratory disease caused by Bordetella pertussis producing severe illness and high mortality, especially among infants. In spite of over $90 \%$ vaccination coverage, the incidence of pertussis is increasing in most developing countries. The aim of this study was to determine the prevalence of Bordetella pertussis in pregnant women in southern part of Tehran, Iran. Methods: Three hundred three pregnant women who referred to health centers for periodic pregnancy tests were randomly selected during six months in the year 2016. After receiving conscious consent from mothers, 5 milliliters of blood was obtained and a questionnaire containing demographic information, occupational status, level of education, mother's age, duration of pregnancy, history of cough and vaccination were completed for each participant. A test to determine quantitative values of IgG and IgA classes antibodies to pertussis toxin (PT IgG, PT IgA) by ELISA method was performed on samples.

Results: In total, 177 women (58.2\%) were serologically infected by Bordetella pertussis. Only 27 women (8.9\%) had cough symptom during pregnancy. The mean levels of PT IgG and PT IgA during pregnancy were 37.24 and 5.79, respectively. The mean PT IgG level in the first trimester of pregnancy was higher than average PT IgG levels around the time of delivery (38.39U/ml versus 34.74U/ml). The association between cough and Immunoglobulins levels was evaluated by chi square test. It was detected that IgA and IgG antibodies titers were related significantly to cough duration over two weeks (P value $<0.001$ ). The IgA titre less than $12 \mathrm{IU} / \mathrm{ml}$ was more associated with pregnant women without a history of cough from two weeks ago.

Conclusion: Due to high exposure of Iranian mothers to pertussis and high prevalence of pertussis among children under the age of six months, it is crucial to prescribe acellular pertussis vaccine in women during pregnancy, upon discharge from the hospital.

Keywords: Pregnancy; Cough; PT IgG; PT IgA; Pertussis

\section{Introduction}

Infectious diseases remain a major cause of mortality among children before 4 years-old. More than 5 million deaths from vaccine-preventable infectious diseases occur in children throughout the world [1]. Vaccination can prevent severe infections and reduce its devastating effects. However, children and infants do not provide suitable immunity in response to many vaccines [2]. A vaccination program against common infections, such as hepatitis B, pertussis and haemophilus influenza usually begins two months after the birth to several following years, but there is no vaccination between childhood and pregnancy in women against vaccine-preventable infectious agents. For this reason, immunization of pregnant women as an important strategy replaces fight against infectious agents in neonatal period [2].

Pertussis is caused by Bordetella pertussis, producing severe illness and high mortality, especially among infants [3]. The incidence of pertussis is increasing in most developed countries despite vaccination coverage of over $90 \%$. The highest prevalence of disease is detected among adults and youth [4]. Vaccination coverage in Iranian population against pertussis is more than $98 \%$. According to the latest statistics in 2011, total 854 cases of pertussis suspected cough were reported in Iran. The overall incidence of disease in the country is 1.12 per 100,000 people. The most frequent occurrence and incidence was reported in 
Mazandaran province(north) with 161 cases (5.22\%) per 100,000 people, followed by the highest incidence in Qazvin (5\%), Qom (4.28\%), Zanjan (4\%) in middle of Iran and Tehran $(1.2 \%)$, respectively.

Pertussis outbreaks occur in cycles (every 2 to 5 years) [5]. Vaccination is the only effective way to fight epidemics. Pregnant women suffering from pertussis during delivery, depending on the onset of infection in the mother, have the ability to infect their children before receiving maternal antibodies through placenta. The duration of immunity with vaccination and natural infection is limited $[6,7]$. Vaccination over than childhood period is necessary to protect newborns [8-10]. The aim of this study was to determine the prevalence of pertussis infection in pregnant women living in Tehran, prevalence of Bordetella pertussis infection among pregnant women and mothers who are not immune and infants at risk of infection.

\section{Materials and methods}

Studied population included all pregnant women who referred to health centers for periodic routine pregnancy tests during six months of the year 2016. According to this study, total 304 pregnant mothers were selected. After obtaining conscious consent from mothers, $5 \mathrm{ml}$ of blood was obtained from the cases and simultaneously a questionnaire was completed for each participant containing demographic information, occupational status, level of education, maternal age, duration of pregnancy, history of cough for more than two weeks in mother and his family, history of vaccination in a child or vaccination history with an acellular vaccine in the previous years. The Ethics Committee approved this research in the Iran University of Medical Sciences Blood samples were centrifuged at about 4000rpm and after serum isolation; it was stored in freezer at minus $20{ }^{\circ} \mathrm{C}$ before analysis. The ELISA test was carried out at Infectious Disease Research Center of Rasool Akram Hospital, Iran University of Medical Sciences. Determination of quantitative values of specific IgG and IgA against pertussis toxins (PT IgG\& IgA) were performed on patients' serum with kit purchased from German IBL Company according to the manufacturer's specification. The results of PT IgG\& IgA were reported as $\mathrm{U} / \mathrm{ml}$. The lowest rate of PT IgG\& IgA determination was 1 and $1 \mathrm{U} / \mathrm{ml}$, respectively. The collected data were analyzed using SPSS software version 24. PT IgG\& IgA levels were reported in $95 \%$ confidence interval in different samples. Pearson tests were used to compare immunoglobulin levels in age groups. P value less than 0.05 was considered statistically significant.

\section{Result}

During six months, 304 pregnant women were enrolled in this study. The mean age at pregnancy was 27.59 years (range 15-45 years). The mean gestational age was 89.03 days. $95 \%$ of women claimed childhood vaccination against pertussis but $5 \%$ of women could not remember their childhood vaccination against pertussis. The distribution of PT IgG levels in mothers' serum during pregnancy. The majority of women had antibody levels of 3.5-221
$\mathrm{U} / \mathrm{ml}$ at 26 weeks of gestation. $58.2 \%$ of women (177 cases) had an antibody level greater than $24 \mathrm{U} / \mathrm{ml}$. PT IgG concentration below $24 \mathrm{U} / \mathrm{ml}$ was reported in 127 (41.8\%) women. PT IgG level greater than $100 \mathrm{U} / \mathrm{ml}$ was observed in (5.92\%) 18 pregnant women.

In total, 177 women (58.2\%) from total 304 women were reported with antibodies level greater than $24 \mathrm{U} / \mathrm{ml}$ and considered positive for pertussis based on German IBL company criteria. Only $27 \%$ (8.9\%) of women had a history of cough during pregnancy. The mean levels of PT IgG and Ig A during pregnancy were 4.82 and $37.5 \%$, respectively. The mean PT IgG antibody level in subjects in the first trimester of pregnancy were higher than levels near delivery in the third trimester of pregnancy (38.39 versus $34.74 \mathrm{U} / \mathrm{ml}$ ) which indicated pertussis infection during pregnancy.

None of the mothers had received an acellular pertussis vaccine during pregnancy. The Pearson test between IgG and IgA levels showed a significant relationship between IgA and IgG levels (P-value $<0.001$ ). This means that if IgA level was less than 10U/ $\mathrm{ml}$, IgG level would be less than $24 \mathrm{U} / \mathrm{ml}$. Evaluation of cough and Immunoglobulin levels showed a significant relationship between IgA and IgG titers and a history of cough duration more than two weeks with Pearson test (P-value<0.001). IgA titer less than 12U/ $\mathrm{ml}$ was related to the absence of cough more than two weeks.

\section{Discussion}

Recently, Center of Disease Control and Prevention (CDC) recommended immunization of pregnant women with Tdap vaccine regardless of prior vaccination during late second trimester and the third trimester of pregnancy, after the $20^{\text {th }}$ week of pregnancy, preferably between weeks 27 to 36 of gestation. The Tdap vaccine Antibody avidity increases with exposure to antigen, which results in selection of high-affinity B-cell lymphocytes. As a result, it is used as an indicator of long-term humoral immunity against pathogen [11].

Despite high levels of vaccination in childhood, we have found evidence that Bordetella infections have spread to 18 pregnant women during pregnancy. 40 women $(13.15 \%)$ had an antibody level of $100-150 \mathrm{U} / \mathrm{ml}$. Although this level is not attributed to recent or active infection, it indicates Bordetella infection in previous year. 53 women (17.3\%) of total 304 pregnant women in our study were serologically positive for Bordetella pertussis during or before gestation, which is much higher than reported cases in this age group by Hashemi et al. [12] in Hamadan (35.8\%), Which indicates an increase in incidence of pertussis in pregnant women and infants under the age of six months. The findings showed that most cases of Bordetella pertussis Infection remained unannounced, possibly due to subclinical period of infection or unsuitable identifying or reporting pertussis by responsible person.

In Russia conducted a study on 102 pregnant women who measured antibody levels against diphtheria, tetanus and pertussis. More than $66 \%$ of pregnant women had no antibodies against pertussis and only $5.22 \%$ had suitable antibody titer 
for protection. The subjects were between 18 to 35 years old [13]. The results from similar studies in other regions reflected different levels of antibody protection, such as 33\% in Spain 55\% in Japan 88\% in Slovenia, and 97\% in Singapore [14-17]. Many of these studies showed increased susceptibility to pertussis in both adolescents and adults, and highlighted necessity for a booster dose in adolescents and adults.

The incidence of Bordetella pertussis infection was reported in 2006 with positive serological evidence of pertussis in Netherlands (6.6\%) and Spain (1.8\%) in 2014. Serological studies in other European countries reported positive pertussis antibodies between 3.3 to $8 \%$. A recent study in pregnant women showed $1.74 \%$ positive antibodies level. In this study, the antibody titer increased within 6 months with increasing in gestational age. In mothers who had positive antibody titers in the first days of pregnancy, exposure to pertussis was occurred before pregnancy.

Mothers who had high level of IgA antibody in the last days of pregnancy, were newly involved. There are some evidence that maternal antibodies protect newborns against pertussis, because PT IgG is transmitted from mother to embryo. Mothers in our study had an antibody level below 40U/ml during pregnancy. Although the protective level of antibodies against pertussis is not defined, but low level of PT IgG is associated with an increased sensitivity to pertussis. In our study, maternal selection errors were happened because $20 \%$ pregnant women in this area were referred to private laboratories for pregnancy tests. Therefore, we estimate that actual number of pertussis infections in these mothers is more than $17.4 \%$. Among limitations of this study, there was no clear correlation between anti PT IgG level and effective protection of serologic antibody levels. Unknown history of vaccination was a limitation in this study. Since interview with participants was a method of collecting information, participants' memory was the only available source of information.

The strengths of this study was that many studies had not been conducted on this population. So that little data was available from infectious source of contact with infants. Therefore, they were a potential source of infection for vulnerable infants (under the age of 2 months). This study announces actual need for further investigation in this group. Despite limitations, the study provided an awareness of maternal safety status. The most effective way to reduce complications of pertussis in infants less than two yearsold is immunization of pregnant women before and during the first trimester of pregnancy with an acellular vaccine. It is also necessary to study polymorphisms of prevalent and dominant strains of pertussis in Iran, which results in low immunity of vaccine used against pertussis in our country [18].

In spite of $99 \%$ vaccination coverage against pertussis in Iran, similar to other countries, the incidence of pertussis increased from the year 2004 (98 cases), 2005 (125 cases) to 2011 (650 cases). The most common cases of pertussis was related to infants under the age of 2 months-old [19,20]. Another study was conducted in 2009-2010 in Iran by Ghorbani et al. [21] on 3629 suspected cases of pertussis, which obtained $6.6 \%$ positive laboratory results. Positive result was more common in women than men $(7.3 \%$ versus $5.9 \%)$ and more relevant in age group under two months-old than those of other age groups ( $\mathrm{P}<0.001)$. These children most likely received pertussis infection from their parents, relatives or medical staff in hospitals [22]. In Spain, hospital's healthcare workers with positive anti-pertussis toxin antibodies were about $31 \%$. as a result, they were more likely to be infected with pertussis bacteria [23]. These people act as a source of infection for susceptible individuals. Unfortunately, there are no accurate data available in our country regarding the incidence of suspected cases of pertussis in hospitals.

\section{Conclusion}

Immunization of health care personnel is the most effective way to reduce the complications of pertussis in newborns and children referring to hospitals and clinics. It is recommended that a study should be carried out in Children and Maternity Hospitals in Tehran in order to assess the level of safety in staff. Due to high exposure of Iranian mothers with pertussis and high prevalence among children under age of six months, it is urgent to use an acellular vaccine in pregnant women during pregnancy, upon discharge from the hospital.

\section{Ethical Approval}

The present study was accepted by the ethics committees of Iran University of Medical Sciences, Iran.

\section{Acknowledgment}

The authors acknowledge Research Center of Pediatric infectious diseases, Rasool Akram Hospital, Iran University of Medical Sciences, Tehran, Iran for their financial support grants.

\section{References}

1. (2013) Organization WH. Global tuberculosis report 2013: World Health Organization.

2. Lambert PH, Liu M, Siegrist CA (2005) Can successful vaccines teach us how to induce efficient protective immune responses? Nat med 11(4): S54-S62.

3. Chiappini E, Stival A, Galli L, Martino MD (2013) Pertussis re-emergence in the post-vaccination era. BMC infectious diseases 13(1):151.

4. Winter K, Harriman K, Zipprich J, Schechter R, Talarico J, et al. (2012) California pertussis epidemic, 2010. J Pediatr 161(6): 1091-1096.

5. Raya BA, Bamberger E, Almog M, Peri R, Srugo I, et al. (2015) Immunization of pregnant women against pertussis: the effect of timing on antibody avidity. Vaccine 33(16): 1948-1952.

6. Melker DHE, Versteegh FG, Schellekens JF, Teunis PF, Kretzschmar M, et al. (2006) The incidence of Bordetella pertussis infections estimated in the population from a combination of serological surveys. J Infect 53(2): 106-113.

7. Plans P, Jansà JM, Doshi N, Harrison TG, Plasència A, et al. (2008) Prevalence of pertussis antibodies in umbilical cord blood samples in Catalonia, Spain. Pediatr Infect Dis J 27(11): 1023-1025.

8. Healy CM, Munoz FM, Rench MA, Halasa NB, Edwards KM, et al. (2004) Prevalence of pertussis antibodies in maternal delivery, cord, and infant serum. J Infect Dis 190(2): 335-340.

9. Rie VA, Wendelboe AM, Englund JA (2005) Role of maternal pertussis antibodies in infants. Pediatr Infect Dis J 24(5): S62-S5. 
10. Gall SA, Myers J, Pichichero M (2011) Maternal immunization with tetanus-diphtheria-pertussis vaccine: effect on maternal and neonatal serum antibody levels. Am J Obstet Gynecol 204(4): 334. e1-. e5.

11. DeSilva M, Vazquez-Benitez G, Nordin JD, Lipkind HS, Romitti PA, et al. (2016) Tdap Vaccination During Pregnancy and Microcephaly and Other Structural Birth Defects in Offspring. Jama 316(17): 1823-1825.

12. Hashemi SH, Zamani M, Mamani M, Javedanpoor R, Rahighi AH, et al (2013) Seroprevalence of Bordetella pertussis antibody in pregnant women in Iran. J Res Health Sci 14(2): 128-131.

13. Za'tsev E, Krasnoproshina LI, Astakhova TI, Zakharova NS (2009) Monitoring of antibodies against diphtheria, tetanus and pertussis in pregnant women. Zh Mikrobiol Epidemiol Immunobiol (1): 32-35.

14. Diez-Domingo J, Ballester A, Baldó JMa, María-Victori P, Villarroya $\mathrm{JV}$, et al. (2004) Incidence of pertussis in persons $\leq 15$ years of age in Valencia, Spain: seroprevalence of antibodies to pertussis toxin (PT) in children, adolescents and adults. Journal of Infection 49(3): 242-247.

15. Okada K, Ueda K, Morokuma K, Kino Y, Tokugawa K, et al. (2004) Seroepidemiologic study on pertussis, diphtheria, and tetanus in the Fukuoka area of southern Japan: seroprevalence among persons 0-80 years old and vaccination program. Jap j infect dis 57(2): 67-71.

16. Sočan M, Prosenc K, Vegnuti M (2006) Seroprevalence of IgG antibodies to pertussis toxin in the Slovene population. Wien kiln Wochenschr 118(11-12): 336-340.
17. Wilder-Smith A, Ng S, Earnest A, Earnest A (2006) Seroepidemiology of pertussis in the adult population of Singapore. Ann Acad Med Singapore 35(11): 780-782.

18. Amirthalingam G, Andrews N, Campbell H, Ribeiro S, Kara E, et al. (2014) Effectiveness of maternal pertussis vaccination in England: an observational study. Lancet 384(9953): 1521-1528.

19. Nikbin VS, Shahcheraghi F, Lotfi MN, Zahraei SM, Parzadeh M, et al. (2013) Comparison of culture and real-time PCR for detection of Bordetella pertussis isolated from patients in Iran. Iran J Microbiol 5(3): 209-214.

20. Zarei S, Jeddi-Tehrani M, Akhondi MM, Zeraati H, Kheirkhah T, et al. (2007) Immunogenicity of a triple diphtheria-tetanus-whole cell pertussis vaccine in Iranian preschool children. Iran J Immunol 4(2): 101-109.

21. Ghorbani G, Zahraei S, Doosti F, Moosazadeh M (2016) Epidemiological Pattern of Bordetella Pertussis in Iran, 2011-2013. Journal of Military Medicine. 17(4): 215-222.

22. Skoff TH, Kenyon C, Cocoros N, Liko J, Miller L, et al. (2015) Sources of Infant Pertussis Infection in the United States. Pediatrics 136(4): 635641.

23. (2012) Statistics and information systems Ministry of Health and Medical Education. Management of Communicable Diseases.

\section{Your next submission with Juniper Publishers will reach you the below assets}

- Quality Editorial service

- Swift Peer Review

- Reprints availability

- E-prints Service

- Manuscript Podcast for convenient understanding

- Global attainment for your research

- Manuscript accessibility in different formats

( Pdf, E-pub, Full Text, Audio)

- Unceasing customer service

Track the below URL for one-step submission https://juniperpublishers.com/online-submission.php 